\title{
Effect of Real-time Physics Organizer Based Smartphone and Indigenous Technology to Students' Scientific Literacy Viewed from Gender Differences
}

\section{Adi Pramuda}

Doctoral Students Postgraduate Program, Universitas Negeri Yogyakarta, Indonesia, adipramuda@ikippgriptk.ac.id

\section{Mundilarto}

Physics Education Program, Faculty of Mathematics and Natural Sciences, Universitas Negeri Yogyakarta Indonesia, mundilarto@uny.ac.id

\section{Heru Kuswanto}

Physics Education, Postgraduate Program, University Negeri Yogyakarta, Indonesia, herukus61@uny.ac.id

\section{Soka Hadiati}

Physics Education, IKIP-PGRI Pontianak, Indonesia, sokahadiati@ikippgriptk.ac.id

This study aims to obtain information regarding the effect of the RPO on students' scientific literacy using global scientific literacy questionnaire (GSLQ) in terms of GSLQ dimension and gender differences. The quantitative research approach is used with experimental methods. The U Mann Whitney, Wilcoxon, T-Test, and descriptive statistics were used to determine whether there were differences in students' global scientific literacy between the control group and the experiment group. The results show that there are no significant differences in students' global scientific literacy between the control and experiment groups, nevertheless, the results in the experiment group show that RPO appears to have significant effects, especially in the habits of mind dimension and across students' gender. Male students in the experiment group are able to show better results on habits of mind dimension than female students. However, female students in the experiment group are able to show a higher increase than the students in the control group.

Keywords: virtual advance organizer, concept attainment, gender, global scientific literacy, traditional technology

Citation: Pramuda, A., Mundilarto, Kuswanto, H., \& Hadiati, S. (2019). Effect of Real-time Physics Organizer Based Smartphone and Indigenous Technology to Students' Scientific Literacy Viewed from Gender Differences. International Journal of Instruction, 12(3), 253-270. https://doi.org/10.29333/iji.2019.12316a 


\section{INTRODUCTION}

The concept that students learn in physics will be better if it is preceded by the provision of basic experience through experimentation activities and connecting with the context of everyday life (Sarjono et al., 2018). Physics concepts understanding will be useful to students' lives as adults and in the 21st-century era, in line with scientific literacy which is the focus of attention for international student assessment (PISA) programs (Tsai, 2015). Scientific literacy in a real-life context is strongly influenced by social structures, traditions, culture, natural conditions, etc. (Sjøberg, 2015). There is the potential of indigenous technology for developing scientific literacy. Indigenous technology is the result of human endeavor and learning process. The learning process experienced by society in the past can be different from modern society, the complexity of the resulting technology can also be different (Baquete et al., 2016; Tapper \& Mclachlan, 2005). Some values that are maintained in the past society have the potential to form a better global society (Mungmachon, 2015). In addition, various indigenous technologies could be studied in relation to the scientific concepts that exist today, especially with the advancement of smartphone technology for the experimentation of various physical phenomena (Pramuda et al., 2018; Vieyra et al., 2015). Analysis of the effects of indigenous technology on physics learning is very useful to form better learning resources. This effort will lead to the development of students' global scientific literacy.

Physics learning with indigenous technology content that is supported by smartphone technology is very important to create a more contextual understanding of physics concepts and preserve local wisdom (Shabrina \& Kuswanto, 2018). In order to organize information which is lead to germane load, the advance organizer has the potential to integrate the use of smartphone and indigenous technology (Korur et al., 2016; Sweller et al., 2011). However, physics media and organizers currently available cannot facilitate the smartphone-assisted concept attainment activities which in real-time involve indigenous technology presented and have not reviewed its influence from a gender perspective. Efforts to investigate, to reach gender-based educational equity, and to reduce gaps of achievement and global scientific literacy by students' is important (Hwang et al., 2018; Torppa et al., 2017). The purpose of this study was to obtain information on the effects of real-time physics organizer (RPO) based on smartphone and indigenous technology in terms of dimensions in the GLSQ and gender. The topic involved is the traditional musical instrument related to the concept of sound waves.

\section{REVIEW OF LITERATURE}

Real and virtual experimentation is very important to inquiry and attains the understanding of concepts through more engaging instructional strategies (Kipnis \& Hofstein, 2007; Lin et al., 2017; Price \& Price-Mohr, 2019). Technological involvement in these efforts, for example, an accelerometer integrated with a smartphone can simplify measurement, clarify results, and implementation in daily life (Vieyra et al., 2015). Technology needs to be involved in learning to improve scientific literacy (Sjøberg, 2015; Tsai, 2014). Current trends in physics experimentation in schools lead to sensor-based inexpensive technology literacy (Bouquet et al., 2019; González et al., 2015). However, there are still inequalities in technological progress between different 
countries and regions. There is a tendency of the unpreparedness of technology. Smartphones that should be able to become media or resource of learning, their use by students is not optimal. Time allocation for students to study less than the total time for social networking and playing games via smartphones (Anshari et al., 2016; Corrigan et al., 2015; Hochberg et al., 2018). The combination of local wisdom-based technology with modern technology turns out to be more innovative in overcoming technological inequality and can build human tolerance to nature and the global environment (Ge, et al., 2015; Pramuda et al., 2018; Riegle-Crumb \& Moore, 2013). In line with Cheema (2017), Hazari et al. (2007), Mun et al. (2013), and Scantlebury et al. (2006), giving attention to students' prior knowledge related to local communities is projected to be able to improve students' global scientific literacy and cross-gender involvement. In a society that still adheres to local wisdom, the technology commonly found is traditional technology (Tapper \& Mclachlan, 2005; Baquete, et al., 2016). Smartphones have reached the traditional community (Roslinda, 2016), however, their use for physics experimentation is still very unfamiliar. Experimentation using modern musical instruments and smartphones as in the research of Konz \& Ruiz (2018), Pereyra et al. (2018), and Yavuz (2015) can be difficult for students from other countries or regions to realize. Students in West Borneo for example, are still more familiar with traditional musical instruments such as Senggayung and Sape' (Suma, 2007; Yusufarief1, 2017).

The existence of various elements of interactivity to develop global scientific literacy form consequences that there will be a lot of information processing. Learning models that motivate students are needed to devote cognitive resources to schema acquisition and automation to process new information and integrate it into existing knowledge structures (Leahy et al., 2015; Sweller et al., 2011). In the family of information processing models, the concept attainment model can facilitate the formation of concepts, the presentation of information organized on various topics or themes, and the stage of development of students (Joyce \& Weil, 2003). The concepts could arise from exploring a sociocultural problem and it would be useful in the stages of knowledge automation and decision making (Besson \& Ambrosis, 2013; Morales, 2014). Not just demonstrating students that the smartphone can be used to measure a certain physical quantity (González et al., 2015; Sung et al., 2016). The concept attainment model needs to be combined with other teaching or learning models such as the advance organizer model. This model is very useful for maintaining the understanding of the concepts that presented in other concept acceptance activities and students will get an overall perspective on all the fields being studied (Joyce \& Weil, 2003; Korur et al., 2016; Van der Meij, 2018). RPO based smartphone and indigenous technology organizing its content according to the combination of the advance organizer and the concept attainment model. Indigenous technology is the themes for apperception and experimentation. Referring Dawkins et al. (2017) and Hazari et al. (2007), real-world examples such as the use of indigenous-based learning materials will be able to increase scientific literacy and in accordance with scaffolding for gender equality. RPO based smartphone and indigenous technology can be made using Ms. Power Point. This is expected to be easier before developing the Android application like those conducted by Arista \& Kuswanto (2018). In line with Reinke (2018), traditional musical instruments 
and configuration of real-time experiments utilizing Spectroid application in RPO can be used to visualize the characteristics of sound outputs. In accordance with Krivoruchko (2018) teachers in real-time can use multitasking and split screen to invite students to observe a pattern and to analyze, assisted with projectors and AnyCast, even with personal computers (PCs), notebooks, and tablets using screen stream over HTTP. The emphasis is students can watch presentations, analyze experimental videos directly, and conduct an experiment with their own gadget.

\section{METHOD}

The study used a quantitative research approach with experimental methods and was conducted from February to May 2018. The control group used the discovery learning model, while the experiment group used a combination of advanced organizer and concept attainment models with real-time physics organizer (RPO) based smartphone and indigenous technology. RPO uses a simple and practical approach to learning so students know that exploring scientific phenomena does not have to be expensive tools.

\section{Participant}

The research subjects are senior high school students (SMA) in Pontianak City, West Borneo (Kalimantan), Indonesia, known as the SMAN 7 Pontianak and were conducted in two classes. The number of students used as research subjects as many as 64 students from 32 students in each class used. Students in the first class used as a control group and students in the second class were used as an experiment group. The physics learning concepts presented to the two groups of student students and related to the study is sound waves concepts.

\section{Instrument}

To collect information on the effect of different learning treatments from the global scientific literacy point of view, students in both groups were given the opportunity to express their perceptions as Global Citizens used questionnaires at the beginning or before learning and at the end or after learning. The instrument used to measure global scientific literacy in the form of a questionnaire was adopted from GSLQ (Mun et al., 2015). Validity and reliability of GSLQ have been calculated using three statistical techniques with a subject of 3.202 students in South Korean. The three techniques used are the Cronbach's $\alpha$ coefficient, exploratory factor analysis (EFA), and confirmatory factor analysis (CFA). GSLQ is an instrument developed based on a new study of the framework of scientific literacy in the 21 st-century. The 21 st-century scientific literacy framework has five dimensions. These five dimensions are content knowledge (core ideas of science, habits of mind (science practices), character and values, science as human endeavor, and metacognition and self-direction. In GSLQ 4 dimensions are involved because assessing content knowledge would require separate measures. The dimensions of GSLQ are derived from elements called factors, and in this study GSLQ dimensions, factors, and items have been translated to Bahasa. The GSLQ consists of 48 items in four dimensions. GSLQ uses five-point Likert-scale, namely: never (1), rarely (2), sometimes (3), often (4), and always (5). 


\section{Data Analysis}

The descriptive statistical analysis was used to describe students' global scientific literacy using GSLQ. The analysis carried out focused on the difference in average scores of the dimensions, factors. items, and also across gender. Statistical tests through SPSS 16.0 were used to determine whether there were differences in students 'global scientific literacy between the control group and the experiment group, and the differences in students' global scientific literacy between before and after learning in the control and experiment groups. Prerequisite tests, namely normality and homogeneity tests are used to determine whether the data is tested parametric or non-parametric.

\section{FINDINGS}

The potential for integration between West Borneo indigenous technology in science (physics) is enormous. It could be used to learn the concepts of sound waves, intensity and sound intensity levels, stationary waves on the strings and air column resonances. It is very significant to use mobile sensors and software that can display measurements with clearer and more accurate visualizations. The teacher's ability to mirror and explain the sensor results on a smartphone screen was very important to a large class of students and could be used by a Dongle or Anycast. Figure 1 shows the design and concept of RPO based smartphone and indigenous technology used in the experiment group. 


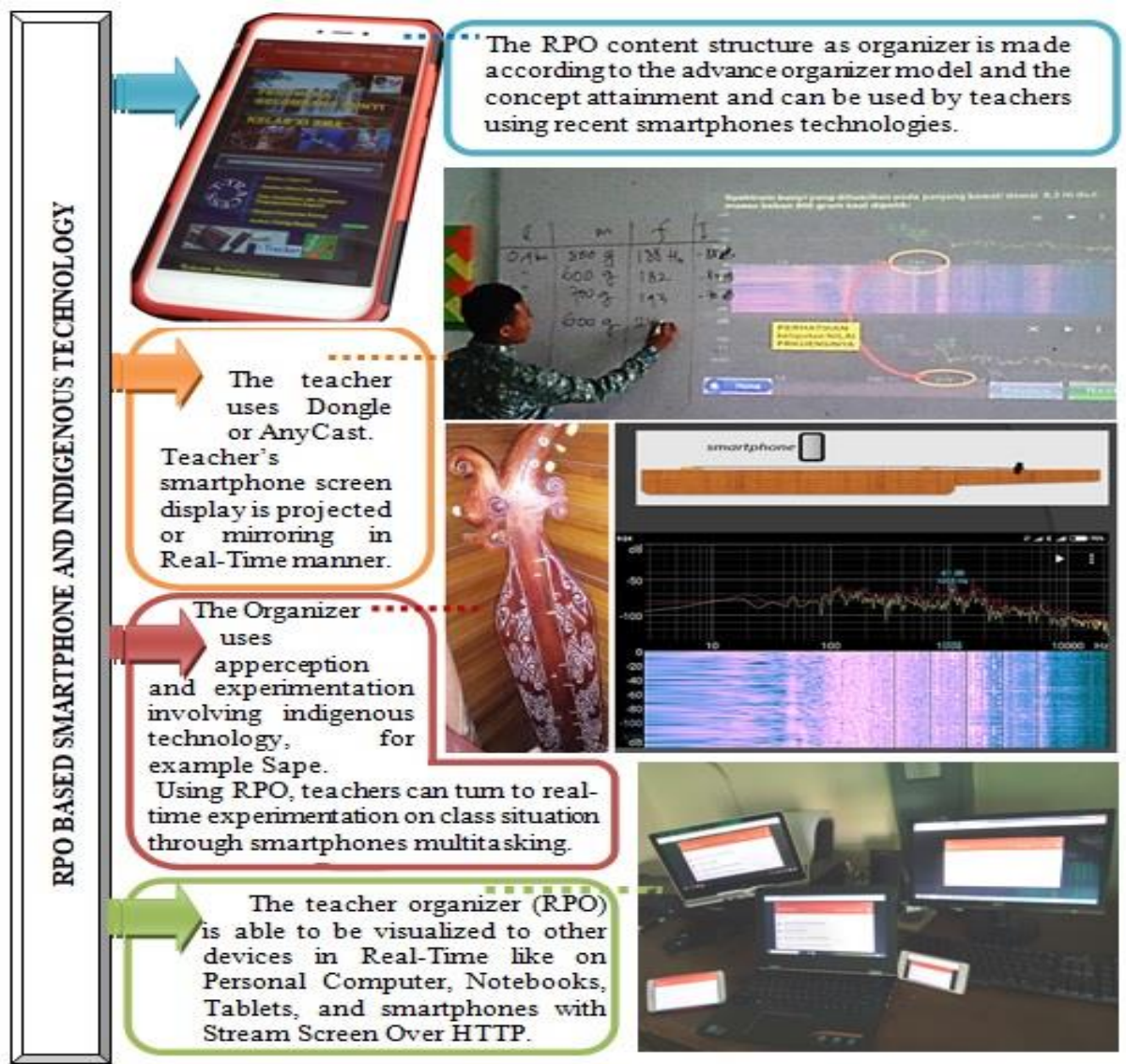

Figure 1

The Design and Concept of RPO Based Smartphone and Indigenous Technology were Used in the Experiment Groups with Physics Concepts Related to Sound Waves.

Students' global scientific literacy is measured at the time before and after learning in the control and experiment group. The average score of students' global scientific literacy in both groups was visualized in Figure 2 and Figure 3. Figure 2 shows that in the experiment group the average GSLQ score for habits of mind; character and values; and science as human endeavor dimension after learning $(3.93,3.66$, and 4.19) is higher than before learning $(3.60,3.62$, and 4.08). In the metacognition and self-direction dimensions, the score before learning (3.81) is higher than after learning (3.73). Reviewing visualization in Figure 3 shows that in the control group the average score for habits of mind and character and values dimensions after learning (3.76 and 3.66) is higher than before learning (3.62 and 3.51). In the dimensions of science as human endeavor and metacognition and self-direction, the average score before learning (4.21 and 3.89) is higher than the average score after learning (4.11 and 3.86). 


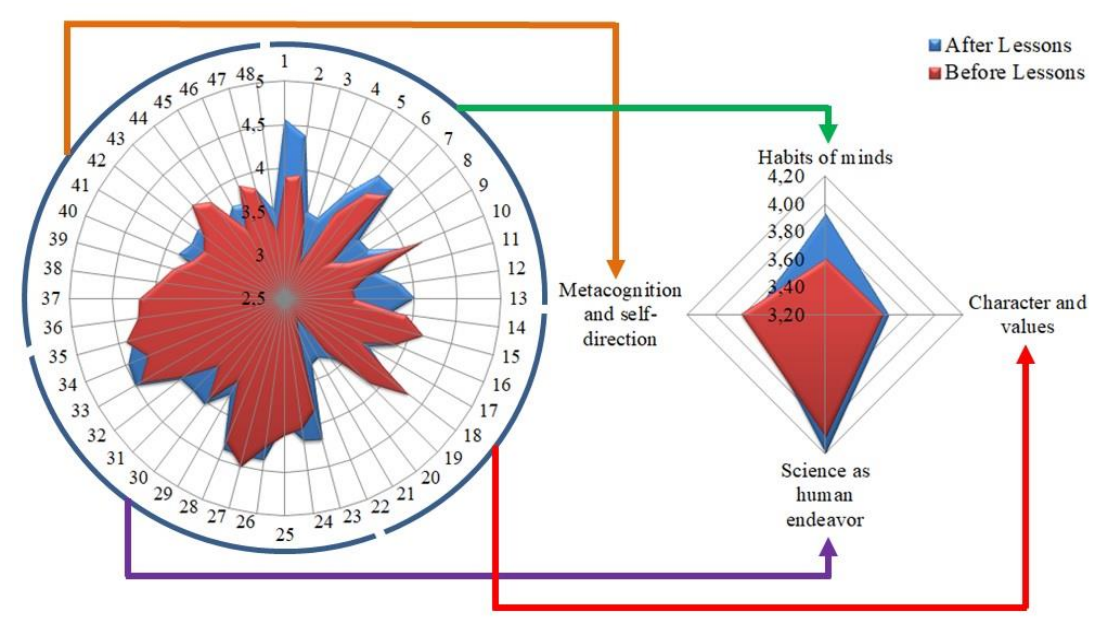

Figure 2

The Average Score of Students' Global Scientific Literacy of the Experiment Group Viewed from the Dimensions and Items in GSLQ.

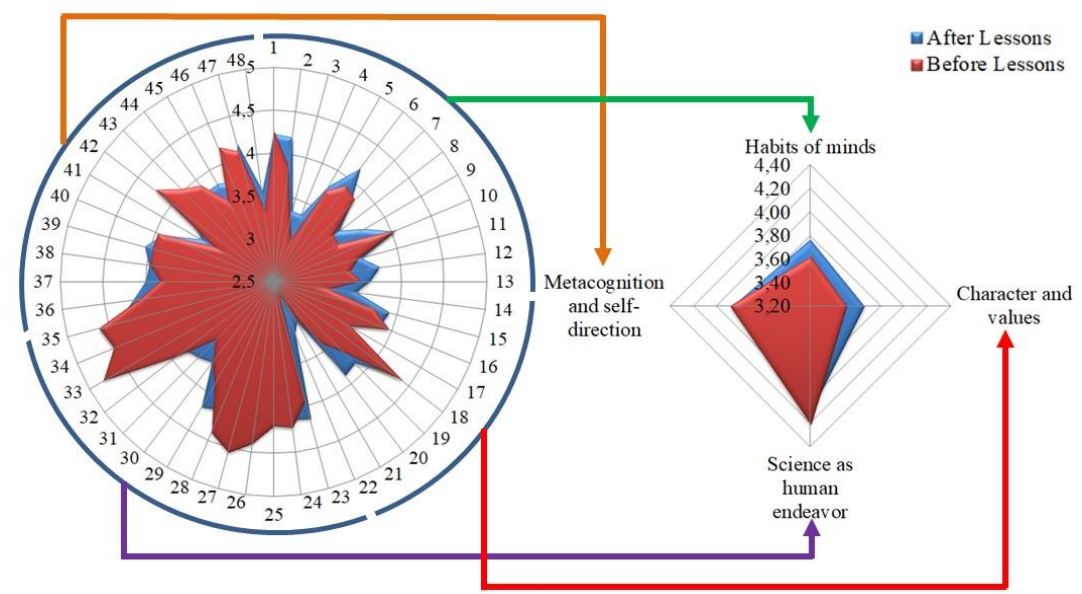

Figure 3

The Average Score of Students' Global Scientific Literacy of the Control Group Viewed from the Dimensions and Items in GSLQ.

In order to ensure the differences in the GSLQ score between both group by reviewing the dimensions that show improvement in Figures 2 and 3, the statistical test was carried out on the dimensions of habits of mind and science as human endeavor. On both dimensions to find out students' global scientific literacy differences between the control and experiment group and differences before and after learning, then first normality and homogeneity of the data were tested and the results summarized in Table 1 and Table 2. 
Table 1

The Results of Normality Data

\begin{tabular}{|c|c|c|c|c|}
\hline \multirow{2}{*}{ Dimension } & \multirow[t]{2}{*}{ Group } & \multicolumn{3}{|c|}{ Kolmogorov-Smirnov } \\
\hline & & Statistic & $\mathrm{df}$ & Sig. \\
\hline \multirow{3}{*}{$\begin{array}{l}\text { Habits of } \\
\text { Mind }\end{array}$} & Experiment Before Lessons & 0.106 & 32 & 0.200 \\
\hline & Experiment After Lessons & 0.097 & 32 & 0.200 \\
\hline & Control After Lesson & 0.122 & 32 & 0.200 \\
\hline \multirow{3}{*}{$\begin{array}{l}\text { Science as } \\
\text { Human } \\
\text { Endeavor }\end{array}$} & Experiment Before Lessons & 0.182 & 32 & 0.009 \\
\hline & Experiment After Lessons & 0.093 & 32 & 0.200 \\
\hline & Control After Lesson & 0.171 & 32 & 0.018 \\
\hline
\end{tabular}

Table 2

The Results of Homogeneity Data

\begin{tabular}{lllll}
\hline \multicolumn{1}{c}{ Dependent Variable } & Levene Statistic & df1 & df2 & Sig. \\
\hline Habits of Mind Before Lessons & 1.135 & 1 & 62 & 0.291 \\
\hline Habits of Mind Sore After Lessons & 2.964 & 1 & 62 & 0.090 \\
\hline Science as Human Endeavor Before Lessons & 0.000 & 1 & 62 & 1.000 \\
\hline Science as Human Endeavor After Lessons & 0.287 & 1 & 62 & 0.594 \\
\hline
\end{tabular}

Table 1 shows that students' score data on habits of mind dimensions before and after learning in the experiment group, and after learning in the control group were normally distributed (Sig.> 0.05). In the dimension of science as human endeavor, only students' score data after learning in the experiment group is normally distributed. Table 2 shows that the data of students' scores on the habits of mind dimension and science as human endeavor before and after learning in the control and experiment group were homogeneous (Sig.> 0.05). According to the results of normality and homogeneity test, U Mann Whitney, Wilcoxon, and t-Test were used to determine whether there were differences in students' global scientific literacy between the control and the experiment group, and to find out whether there were differences in before and after learning in the experiment group. The results of the statistical test are presented in Table 3.

Table 3

The Results of Statistics Test

\begin{tabular}{lll}
\hline \multicolumn{1}{c}{ Variable } & Test & Sig. \\
\hline Habits of Mind Control-Experiment Group & Independent Samples & 0.216 \\
\hline Science as Human Endeavor Control-Experiment Group & Mann-Whitney U & 0.505 \\
\hline Habits of Mind Before-After Lessons Experiment Group & Paired Samples & 0.003 \\
\hline $\begin{array}{l}\text { Science as Human Endeavor Before-After Lessons } \\
\text { Experiment Group }\end{array}$ & Wilcoxon & 0.290 \\
\hline
\end{tabular}

Table 3 shows there is no significant difference of students' global scientific literacy score on habits of mind and science as human endeavor dimensions between the experiment group and the control group (2-tailed Sig.> 0.05 and Asymp. Sig.> 0.05). There is significant difference score of students' global scientific literacy score on habits of mind dimensions between before and after learning in the experiment group (Sig.< 0.05). However, there is no significant differences score of students' global scientific 
literacy on science as human endeavor dimensions between before and after learning in the experiment group (Sig.> 0.05). In order to find more clearly the differences in the pattern of the students GSLQ score from a gender perspective, then further in Figure 4.a and Figure 4.b presented the average scores in the habits of mind and science as human endeavor dimension between male and female students in the control and experiment groups before and after learning.

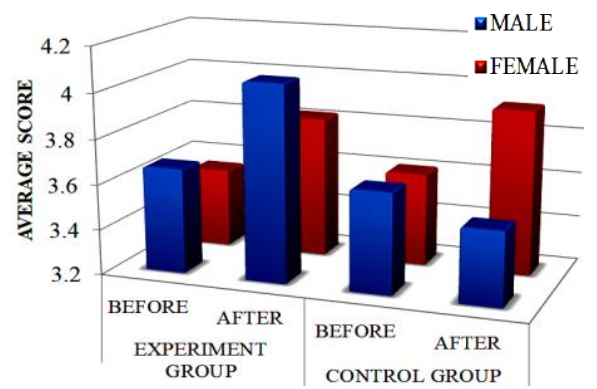

Figure 4. a.

The Average Score of Habits of Mind Dimensions in the Experiment Group and the Control Group Reviewed from Gender.

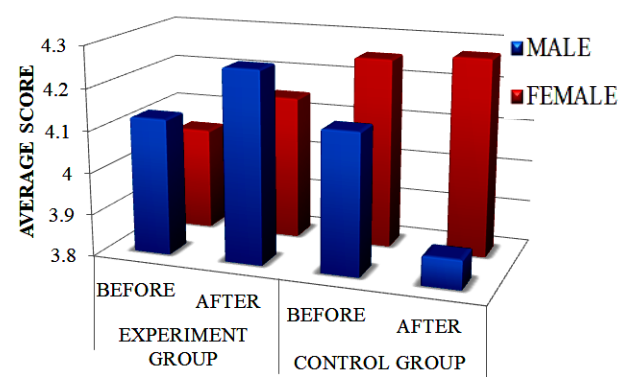

Figure 4 .b.

The Average Score of Science as Human Endeavor Dimensions in the Experiment Group and the Control Group Reviewed from Gender.

In the dimensions of habits of mind, the average GSLQ score of male students before learning in the experiment group was 3.66 and the average score of female students was 3.55. In the control group respectively was 3.64 and 3.61. The average GSLQ score of male students after learning in the experiment group was 4.07 and the average score of female students was 3.82. In the control group respectively was 3.53 and 3.93. When reviewed the GSLQ average score of male students after learning in the experiment group, the value is higher than before learning with a difference of 0.40 . In the control group was lower with a difference of 0.12 . The average GSLQ score of female students after learning in the experiment group was higher than before learning with a difference of 0.27 . In the control group was higher with a difference of 0.32 .

In the dimension of science as human endeavor, the average GSLQ score of male students before learning in the experiment group was 4.13 and the average score of female students was 4.05. In the control group respectively was 4.14 and 4.26 . The average GSLQ score of male students after learning in the experiment group was 4.26 and the average score of female students was 4.15. In the control group respectively was 3.87 and 4.27. The GSLQ average score of male students after learning in the experiment group, the value is higher than before learning with a difference of 0.13 . In the control group was lower with a difference of 0.27 . The average GSLQ score of female students after learning in the experiment group was higher than before learning with a difference of 0.10. In the control group was higher with a difference of 0.02.

In the dimensions of habits of mind, the use of RPO based smartphone and indigenous technology in the experiment group is equally beneficial in terms of gender. Significant 
differences in the results that are better for male students. Furthermore, in the dimensions of science as human endeavor, RPO based smartphone and indigenous technology were also found to be equally beneficial in terms of gender, with a slight difference in the results of better scores in male students. In the experiment groups, the scores of male and female students were higher than before learning. The control group scores also showed a higher than before learning, however, the difference showed that the increase was still lower when compared to students in the experiment group. The average GSLQ score of male students in the control group even decreased on the dimensions habits of mind and science as human endeavor.

\section{DISCUSSION}

It has been presented visually from the overall dimensions of GSLQ that between the control and experiment groups there seems to be a difference, this difference is very slight. This shows that the implementation of the discovery learning models compared to the learning model combination between the advance organizer and the concept attainment model can reach almost the same level of global scientific literacy. In line with Joyce \& Weil (2003), Korur et al. (2016), and Sweller et al. (2011) this is due to the direction of the development of models involving RPO still in the characteristics of developing information processing family models as well as discovery learning models. The learning tends to increase the ability of students more towards the factors that exist in the dimensions of habits of mind than the other three GSLQ dimensions, the contribution of this increase becomes insignificant. Previously, in the experiment group, the habits of mind dimension show a higher average score and increase than the control group. In the experiment group, students attain the concept or scientific ideas in a complete and comprehensive manner. The availability of time to focus on exploring with RPO motivates students to share scientific ideas and give useful feedback. The combination of the learning model encourages students to collect data or information in an organized way including learning to find patterns in experimental data.

Reviewing the difference in scores, this is certainly inseparable from the effects of RPO based smartphones and indigenous technology in terms of gender. Referring to the research of Jugovic (2017) and Miller (2006) it is very possible that there is a difference in global scientific literacy using GSLQ across gender. RPO can facilitate the students' communication and collaboration skills and also systematic thinking/information management skills, especially for male students. In the experiment group, male students showed a higher increase than female students, while in the control group the opposite results happened which is indicated that their skills were not facilitated. Male students show the ability to think systemically in managing information with diverse or divergent strategies, like challenges and spend more time preparing problem-solving steps, while female students tend to adapt to a small number of strategies that they feel are not big challenges, focus on problem-solving efforts (Mun et al., 2015). Furthermore, in line with Shi et al. (2016), when learning using RPO male students are happier and more able to demonstrate their ability to explore a physical phenomenon or do scientific experimentation using smartphone sensors and their applications than female students. Research by Wulff et al. (2018) reinforce the results obtained in the study that male 
students show more interest in a deal with physics stuff during learning and leisure time. Referring to the study of Anshari et al. (2016) it has been found that compared to male students, female students are more interested and spend more time on social networking. In line with the research of Traxler et al. (2018) found that female students showed more verbal reasoning than male students who showed more spatial reasoning. Female students in the experiment group can show their role when taking into account the goals of the group and give useful feedback to others, while male students are better able to show their role when collecting information and data in an organized way, and are easily motivated with diverse or divergent strategies and also like challenges, for example when measuring with a variety of app. related to sensors smartphones.

The dimension of science as human endeavor on GLSQ consists of the factors of characteristics of scientific knowledge and science and society/spirit of science. Consistent with the research of Pereyra et al. (2018), in the experiment group students can recognize that an idea of science can change when new evidence is found and can be derived from observations of phenomena in nature, for example, students initially assume that many objects are similar to the string will only produce a single frequency spectrum and Melde's Law is difficult to explore, however after using RPO it can be explored easily. Students become enthusiastic to find problems solutions. They feel for themselves that being a scientist must be open-minded and skeptical, and try to design research and report data obtained honestly. Indigenous technology themes in RPO helping students to connect with concrete examples of the relationship between science, technology, and society. Figure 5 shows that male students are very enthusiastic about experimenting using RPO.

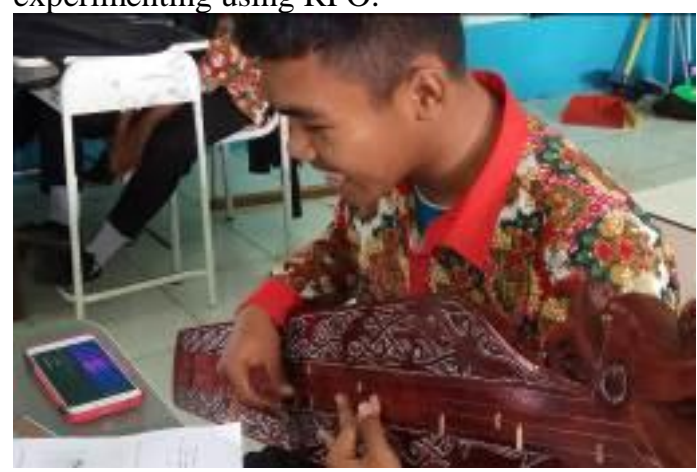

Figure 5

Male Students Enthusiastically Investigate Sape' Sound Frequency Spectrum, the Results can be Visualized to Other Students.

Sape' has its own uniqueness because the kind of string used in each fret has not differed, so that the variation in string tension and string length for the resulting sound frequency spectrum can be used to study Melde's Law. Students also can find out the influence of distance on the sound intensity level. In West Borneo, Sape' is adept at being played by male students, no rules prohibiting women from using it. Students have 
equal opportunities to learn to use it as well as other traditional musical instruments such as Senggayung to learn the concept of resonance in air columns.

The students from the two groups showed a tendency toward higher average scores for science as human endeavor dimension, whereas the lowest was in character and values dimension. The lowest average scores were different from the Australian, Chinese, and Korean Middle School Students that showed a tendency toward higher scores for science as human endeavor and the lowest scores were in meta-cognition and selfdirection (Mun et al., 2013). The slight difference in scores between before and after learning as well as in the control group shows that RPO based smartphone and indigenous technology can maintain the self-confidence and the desire to look for scientific evidence and information about global issues. Although RPO is something new for students, however, students can feel and understand in advance all aspects of the problem that will be studied in learning from the organizer. Students can understand the relationship between the problem and the objectives to be achieved. Students can review their work during learning. Referring to Marshman et al. (2018) and Wulff et al. (2018) this aspect is very important and describes students who learn with RPO can achieve a positive self-direction. The concept attainment in the RPO is properly planned, aligned with the research of Dos (2014) and Kipnis \& Hofstein (2007) RPO can show the role of giving students an opportunity to practice metacognitive skills and potentially improve academic achievement.

The organization of physics learning resources on RPO allows students to focus on the learning objectives and group goals that are formed, even though the organizer is only made using PowerPoint. This result is better than Remón et al. (2017) because the teacher and student devices in this study can be synergistically harmonized. Nevertheless, reviewing the average score is still low on the character and values dimension, refer to PISA Released Item CS613 Fossil Fuels Unit \#1-2 (OECD, 2015). A tendency toward the lowest average scores in character and values dimension is more due to the traditional technology issues need to be presented more concretely with documentation or example that students' personal behaviors can influence the environment throughout the world. Thus, RPO still needs to be developed in further research so students can be involved to take part in decision-making activities about issues that affect the world. For example, collaborating the knowledge of sensor and sophistication of social media facilitated in smartphones on activities helping a community or institution engaged in the preservation of culture and the natural environment. For female students, this will primarily provide a better basis for improving scientific literacy. In line with Gautier (2012), students need to know how traditional musical instruments are made and have a connection with nature conservation. Reviewing Buchholz \& Pyles (2018), the ability of students to repeat RPO independently after learning at school needs to be trained continuously. RPO based smartphone and indigenous technology innovation are very urgent to be studied, applied, and become an effort to educate students to understand various ways for indigenous knowledge preservation, using gadgets especially smartphones wiser in school, responsible as global citizens, and actively communicating and collaborating. 


\section{CONCLUSION}

RPO based smartphone and indigenous technology in the research conducted is something new for teachers and students. There are no significant differences in students' global scientific literacy between the control and experiment groups, nevertheless, the results in the experiment group show that RPO appears to have significant effects to develop global scientific literacy, especially in the habits of mind dimension, and across students' gender. Male students are able to show better results on habits of mind dimension than female students because they already have a better base of prior knowledge related to smartphone technology and traditional technology formed from their daily activities. However, female students who studied using RPO able to achieve a higher increase in global scientific literacy than the students who only followed conventional learning. RPO can increase self-confidence and desire to learn to look for scientific evidence and information related to global issues. Reviewing character and values dimension, RPO still needs to be developed with real decisionmaking activities about issues that affect the world in accordance with the sophistication of today's smartphone technology.

\section{ACKNOWLEDGMENT}

This research was supported by The Ministry of Research Technology and The Higher Education Republic of Indonesia. Research Grant No. 001/L.202.103/PDD/III/2018.

\section{REFERENCES}

Anshari, M., Alas, Y., Hardaker, G., Jaidin, J. H., Smith, M., \& Ahad, A. D. (2016). Smartphone habit and behavior in Brunei: Personalization, gender, and generation gap. Computers in Human Behavior, 64, 719-727. doi: 10.1016/j.chb.2016.07.063.

Arista, F. S., \& Kuswanto, H. (2018). Virtual physics laboratory application based on the Android smartphone to improve learning independence and conceptual understanding. International Journal of Instruction, 11(1), 1-16. doi: 10.12973/iji.2018.1111a.

Baquete, A. M., Grayson, D., \& Mutimucuio, I. V. (2016). An exploration of indigenous knowledge related to physics concepts held by Senior Citizens in Chókwé, Mozambique. International Journal of Science Education, 38(1), 1-16. doi: 10.1080/09500693.2015.1115137.

Besson, U., \& De Ambrosis, A. (2013). Teaching energy concepts by working on themes of cultural and environmental value. Science \& Education, 23(6), 1309-1338. doi: 10.1007/s11191-013-9592-7.

Bouquet, F., Dauphin, C., Bernard F., \& Bobroff, J. (2019). Low-cost experiments with everyday objects for homework assignments. Physics Education, 54(2): 025001. doi: 10.1088/1361-6552/aaf6d6. 
Buchholz, B. A., \& Pyles, D. G. (2018). Scientific literacy in the wild: Using multimodal texts in and out of school. The Reading Teacher, 72(1), 61-70. doi: $10.1002 / \operatorname{trtr} .1678$.

Cheema, J. R. (2017). Cross-country gender DIF in PISA science literacy items. European Journal of Developmental Psychology, 16(2), 1-15. doi: 10.1080/17405629.2017.1358607.

Corrigan, D., Buntting, C., Dillon, J., Jones, A., \& Gunstone, R. (2015). The future in learning science: What's in it for the learner? Switzerland: Springer International Publishing. doi: 10.1007/978-3-319-16543-1.

Dawkins, H., Hedgeland, H., \& Jordan, S. (2017). Impact of scaffolding and question structure on the gender gap. Physical Review Physics Education Research, 13(2), 0201171-0201178. doi: 10.1103/PhysRevPhysEducRes.13.020117.

Dos, B. (2014). The relationship between mobile phone use, metacognitive awareness and academic achievement. European Journal of Educational Research, 3(4), 192-200. doi: 10.12973/eu-jer.3.4.192.

Gautier, C. (2012). A new type of debate for global warming and scientific literacy. Cultural Studies of Science Education, 7(3), 683-691. doi:10.1007/s11422-012-9417-z.

Ge, X., Ifenthaler, D., \& Michael Spector, J. M. (2015). Emerging technologies for STEAM education. Switzerland: Springer International Publishing. doi: 10.1007/978-3319-02573-5.

González, M. A., Martín, M. E., Llamas, C., Martínez, O., Vegas, J., Herguedas, M., \& Hernández, C. (2015). Teaching and learning physics with smartphones. Journal of Cases on Information Technology, 17(1), 31-50. doi: 10.4018/978-1-5225-07833.ch044.

Hazari, Z., Tai, R. H., \& Sadler, P. M. (2007). Gender differences in introductory university physics performance: The influence of high school physics preparation and affective factors. Science Education, 91(6), 847-876. doi: 10.1002/sce.20223.

Hochberg, K., Kuhn, J., \& Müller, A. (2018). Using smartphones as experimental toolseffects on interest, curiosity, and learning in physics education. Journal of Science Education and Technology, 27(5), 385-403. doi:10.1007/s10956-018-9731-7.

Hwang, J., Choi, K. M., Bae, Y., \& Shin, D. H. (2018). Do teachers' instructional practices moderate equity in mathematical and scientific literacy? An investigation of the PISA 2012 and 2015. International Journal of Science and Mathematics Education, 16(Suppl.1), 25-45. doi: 10.1007/s10763-018-9909-8.

Joyce, B., \& Weil, M. (2003). Models of teaching (5 $5^{\text {th }}$ edition). New Delhi: PrenticeHall of India Private Limited. 
Jugovic, I. (2017). Students' gender-related choices and achievement in physics. Center for Educational Policy Studies Journal, 7(2), 71-95. https://files.eric.ed.gov/fulltext/EJ1145817.pdf.

Kipnis, M., \& Hofstein, A. (2007). The inquiry laboratory as a source for development of metacognitive skills. International Journal of Science and Mathematics Education, 6(3), 601-627. doi: 10.1007/s10763-007-9066-y.

Konz, N. \& Ruiz, M. J. (2018). Amplitude, frequency, and timbre with the French horn. Physics Education, 53(4): 045004. doi:10.1088/1361-6552/aabbc1.

Korur, F., Toker, S. \& Eryılmaz, A. (2016). Effects of the integrated online advance organizer teaching materials on students' science achievement and attitude. Journal of Science Education and Technology, 25(4), 628-640. doi: 10.1007/s10956-016-9618-4.

Krivoruchko, D. (2018). Screen stream over HTTP. Retrieved 22 February, 2018 from https://play.google.com/store/apps/details?id=info.dvkr.screenstream.

Leahy, W., Hanham, J., \& Sweller, J. (2015). High element interactivity information during problem solving may lead to failure to obtain the testing effect. Educational Psychology Review, 27(2), 291-304. doi: 10.1007/s10648-015-9296-4.

Lin, S. Y., Aiken, J. M., Seaton, D. T., Douglas, S. S., Greco, E. F., Thoms, B. D., \& Schatz, M. F. (2017). Exploring physics students' engagement with online instructional videos in an introductory mechanics course. Physical Review Physics Education Research, 13(2), 0201381-02013818. doi: 10.1103/PhysRevPhysEducRes.13.020138.

Marshman, E. M., Kalender, Z. Y., Nokes-Malach, T., Schunn, C., \& Chandralekha Singh. (2018). Female students with A's have similar physics self-efficacy as male students with C's in introductory courses: A cause for alarm? Physical Review Physics Education Research, 14, 020123. doi: 10.1103/PhysRevPhysEducRes.14.020123.

Miller, P. H., Blessing, J. S., \& Schwartz, S. (2006). Gender differences in high-school students' views about science. International Journal of Science Education, 28(4), 363 381. doi: 10.1080/09500690500277664.

Morales, M. P. E. (2014). The impact of culture and language sensitive physics on concept attainment. International Journal of Learning, Teaching and Educational Research, 2(1), 1-29. https://www.ijlter.org/index.php/ijlter/article/view/33/5.

Mun, K., Lee, H., Kim, S. W., Choi, K., Choi, S. Y., \& Krajcik, J. S. (2013). Crosscultural comparison of perceptions on the global scientific literacy with Australian, Chinese, and Korean middle school students. International Journal of Science and Mathematics Education, 13(S2), 437-465. doi: 10.1007/s10763-013-9492-y.

Mun, K., Shin, N., Lee, H., Kim, S. W., Choi, K., Choi, S. Y., \& Krajcik, J. S. (2015). Korean secondary students' perception of scientific literacy as global citizens: Using Global Scientific Literacy Questionnaire. International Journal of Science Education, 37(11), 1739-1766. doi: 10.1080/09500693.2015.1045956. 
Mungmachon, M. R. (2012). Knowledge and local wisdom: Community treasure. International Journal of Humanities and Social Science, 2(13), 174-181. http://www.ijhssnet.com/journals/Vol_2_No_13_July_2012/18.pdf.

OECD. (2015). Programme for international student assessment (PISA) released field trial cognitive items. Retrieved 17 May, 2018 from http://www.oecd.org/pisa/test/PISA2015-Released-FT-Cognitive-Items.pdf.

Pereyra, C. J., Osorio, M., Laguarda, A., \& Gau, D. L. (2018). Fourier analysis of a vibrating string through a low-cost experimental setup and a smartphone. Physics Education, 53(4), 045019. doi: 10.1088/1361-6552/aac488.

Pramuda, A., Mundilarto, Kuswanto, H., \& Hadiati, S. (2018). Utilising "Meriam Karbit" indigenous knowledge to construct alternative physics experiments-based smartphone camera. IOP Journal of Physics: Conference Series, 1108/012007, 1-6. doi: 10.1088/1742-6596/1108/1/012007.

Price, C. B., \& Price-Mohr, R. (2019). PhysLab: a 3D virtual physics laboratory of simulated experiments for advanced physics learning. Physics Education, 54: 035006. doi: 10.1088/1361-6552/ab0005.

Reinke, C. (2018). Spectroid. Retrieved 05 May, 2018 from https://play.google.com/store/apps/details?id=org.intoorbit.spectrum.

Remón, J., Sebastián, V., Romero, E., \& Arauzo, J. (2017). Effect of using smartphones as clickers and tablets as digital whiteboards on students' engagement and learning. Active Learning in Higher Education, 18(2), 173-187. doi: 10.1177/1469787417707618.

Riegle-Crumb, C., \& Moore, C. (2013). The gender gap in high school physics: Considering the context of local communities. Social Science Quarterly, 95(1), 253268. doi: $10.1111 /$ ssqu. 12022 .

Roslinda, E. (2016). Dayak desa forest land use system as social capital to acquire forest management rights in West Kalimantan, Indonesia. Biodiversitas, 17(1), 177-184. doi: 10.13057/biodiv/d170126.

Sarjono, Mardapi, D., \& Mundilarto. (2018). Development of physics Lab assessment instrument for senior high school level. International Journal of Instruction, 11(4), $17-$ 28. doi: 10.12973/iji.2018.1142a.

Scantlebury, K., Baker, D., Sugi, A., Yoshida, A., \& Uysal, S. (2006). Avoiding the Issue of Gender in Japanese Science Education. International Journal of Science and Mathematics Education, 5(3), 415-438. doi:10.1007/s10763-006-9045-8.

Shabrina, \& Kuswanto, H. (2018). Android-assisted mobile physics learning through Indonesian Batik culture: Improving students' creative thinking and problem solving. International Journal of Instruction, 11(4), 287-302. doi: 10.12973/iji.2018.11419a. 
Shi, W. Z., Sun, J., Xu, C., \& Huan, W. (2016). Assessing the use of smartphone in the university general physics laboratory. EURASIA Journal of Mathematics, Science \& Technology Education, 12(1), 125-132. doi: 10.12973/eurasia.2016.1424a.

Sjøberg, S. (2015). PISA and global educational governance-a critique of the project, its uses and implications. EURASIA Journal of Mathematics, Science \& Technology Education, 11(1), 111-127. doi: 10.12973/eurasia.2015.1310a.

Suma, F. (2007). Deskripsi seni musik dan alat musik idiophone Senggayung. Ketapang: Kantor Informasi Kebudayaan dan Pariwisata. Retrieved 2 February, 2019 from http://www.pustaka-bpnbkalbar.org/pustaka/diskripsi-musik-dan-alat-musikidiophone-senggayung.

Sung, Y. T., Chang, K. E., \& Liu, T. C. (2016). The effects of integrating mobile devices with teaching and learning on students' learning performance: A meta-analysis and research synthesis. Computers \& Education, 94, 252-275. doi: 10.1016/j.compedu.2015.11.008

Sweller, J., Ayres, P., \& Kalyuga, S. (2011). Cognitive load theory. New York: Springer Science Business Media, LLC. doi: 10.1007/978-1-4419-8126-4.

Tapper, R., \& Mclachlan, K. (2005). Technology tradition and survival aspects of material culture in the Middle east and Central Asia. London: Frank Cass Publishers.

Torppa, M., Eklund, K., Sulkunen, S., Niemi, P., \& Ahonen, T. (2017). Why do boys and girls perform differently on PISA reading in Finland? The effects of reading fluency, achievement behavior, leisure reading and homework activity. Journal of Research in Reading, 41(1), 122-139. doi: 10.1111/1467-9817.12103.

Traxler, A., Henderson, R., Stewart, J., Stewart, G., Papak, A., \& Lindell, R. (2018). Gender fairness within the force concept inventory. Physical Review Physics Education Research, 14, 010103. doi: 10.1103/PhysRevPhysEducRes.14.010103.

Tsai, C. Y. (2014). Improving students' PISA scientific competencies through online argumentation. International Journal of Science Education, 37(2), 321-339. doi: 10.1080/09500693.2014.987712.

Van der Meij, H. (2018). Advance organizers in videos for software training of Chinese students. British Journal of Educational Technology, 50(3), 1368-1380. doi: 10.1111/bjet.12619.

Vieyra, R., Vieyra, C., Marti, A., Monteiro, M., \& Jeanjacquot, P. (2015). Turn your smartphone into a science laboratory. The Science Teacher, 82(9), 32-39.

Wulff, P., Hazari, Z., Petersen, S., \& Neumann, K. (2018). Engaging young women in physics: An intervention to support young women's physics identity development. Physical Review Physics Education Research, 14, 020113. doi: 10.1103/PhysRevPhysEducRes.14.020113. 
Yavuz, A. (2015). Measuring the speed of sound in air using smartphone applications. Physics Education, 50(3), 281-284. doi: 10.1088/0031-9120/50/3/281.

Yusufarief1 (2017). 10 Alat Musik Tradisional Kalimantan Barat yang Bersejarah. Retrieved 8 August, 2017 from https://rumahulin.com/alat-musik-tradisionalkalimantan-barat/ 